\title{
COMPETÊNCIAS EMPREENDEDORAS E SATISFAÇÃO NO TRABALHO SE REFLETEM NO DESEMPENHO ORGANIZACIONAL EM EMPRESAS DE MICRO E PEQUENO PORTE?
}

Suely Parente Moretto ${ }^{1}$ Amelia Silveira $^{2}$

Déborah Luiza Marcon ${ }^{3}$

${ }^{1}$ FACULDADE LUCIANO FEIJAO

${ }^{2}$ Universidade Federal de Santa Catarina

${ }^{3}$ Universidade Estadual do Oeste do Paraná 


\section{COMPETÊNCIAS EMPREENDEDORAS E SATISFAÇÃO NO TRABALHO SE REFLETEM NO DESEMPENHO ORGANIZACIONAL EM EMPRESAS DE MICRO E PEQUENO PORTE?}

Resumo: O desempenho organizacional tem requerido comportamentos empreendedores nas organizações, e a satisfação no trabalho é fator importante para esse desempenho. Objetivou-se avaliar a relação positiva entre as competências empreendedoras e a satisfação no trabalho com o desempenho organizacional de micro e pequenas empresas, em cidade do Nordeste do Brasil. Foram pesquisadas 35 empresas que apresentavam o Setor de Recursos Humanos estruturado, com Gestor de Recursos Humanos. A pesquisa foi descritiva, com método quantitativo. Adotaram-se questionários para a coleta de dados. A análise estimou média, desvio padrão, coeficiente de variação, assimetria e curtose de cada variável; adotou a análise de variância (ANOVA) e a análise de correlação. Os resultados confirmaram, positivamente, as três hipóteses do estudo. Ficou evidente o forte índice do conjunto de planejamento quando comparado à satisfação no trabalho e ao impacto significativo sobre o desempenho.

Palavras-chave: Competências empreendedoras. Satisfação no trabalho. Desempenho organizacional. Micro e pequenas empresas.

\section{Introdução}

O mundo do trabalho está mais complexo e em constante dinamismo. Por isso são muitas as estratégias utilizadas pelos gestores para aumentar a competitividade, driblar a concorrência, surpreender os clientes e garantir o sucesso do empreendimento. Os ambientes organizacionais modificaram seus aspectos competitivos, principalmente referente às pessoas. Realizar algo único, que não pode ser copiado, e que se constitua em diferencial competitivo da empresa, está relacionada às pessoas, ao grupo de trabalho e ao desenvolvimento de um ambiente capaz de gerar nelas potencial inovador, senso de realização, sentimento de pertencer e satisfação no trabalho. Assim, o capital intelectual das empresas e a satisfação das pessoas no ambiente de trabalho tornam-se ferramentas que auxiliam e distinguem um negócio de outro. Identificar talentos e formar a estrutura necessária para, de fato, estruturar cada setor com as pessoas necessárias para o desenvolvimento das atividades e atingimento dos objetivos organizacionais constitui uma das tarefas dos Recursos Humanos (RH).

Assim, conseguir profissionais capazes de contribuir com ideias, que sejam competentes, dinâmicos, provoquem mudanças e permaneçam em suas organizações tem sido o desafio dos gestores de pessoas nos RHs. Quando as pessoas encontram satisfação em seu trabalho, inicia-se uma parceria em que ambos os atores ganham, tanto a empresa quanto o colaborador. Pessoas com índice elevado de satisfação com seu trabalho são propensas a valorizar mais seu labor e, por conseguinte, poderão ser mais produtivas e ter melhor desempenho. Mesmo sendo esse assunto um tema difícil de ser explicado, pelos muitos aspectos subjetivos que o envolvem, revela-se uma importante tarefa o avaliar nas organizações, para fazer o ajuste periódico do alinhamento de interesses e garantir que os propósitos organizacionais sejam alcançados por uma força de trabalho motivada (Medeiros, Santos, Dantas, \& Minuzzi, 2007).

O objetivo deste trabalho é avaliar a existência de relação positiva entre as competências empreendedoras e a satisfação no trabalho e o desempenho dos funcionários da área de RH das micro e pequenas empresas da Cidade de Sobral. Procurou-se, assim, identificar o perfil

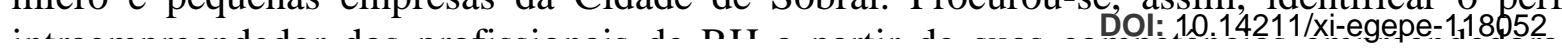


levantar o grau de satisfação no trabalho dos profissionais de RH e mensurar o desempenho de RH a partir da avaliação dos funcionários.

Como contribuição da pesquisa espera-se que os resultados possam dar subsídios às organizações para compreenderem melhor o universo referente à satisfação das pessoas no ambiente de trabalho, o que pode levar a empresa a ter melhor desempenho.

\section{Compreendendo as competências}

Competência é, por característica, a capacidade de entrega do indivíduo (de suas habilidades, conhecimentos e atitudes) para a organização. Por ser um tema atual, os fatos permitem afirmar que o conceito de competência não é um modismo; ao contrário, tem se mostrado muito adequado para explicar a realidade vivida pelas empresas na gestão de pessoas. Ao mesmo tempo, entretanto, é um conceito em construção (Dutra, 2004).

A competência é percebida como o estoque de recursos que o indivíduo detém. Embora o foco de análise seja o indivíduo, é importante alinhar as competências às necessidades estabelecidas pelos cargos ou posições existentes nas organizações (Fleury \& Fleury, 2001). Ter competência significa, de maneira geral, intercalar conhecimentos (saber), habilidades (saber fazer) e atitudes (querer).

O conhecimento corresponde ao saber acumulado pelo colaborador ao longo de sua vida, e a habilidade corresponde ao saber o que fazer. A atitude, por sua vez, é o querer fazer e está relacionada aos aspectos sociais e afetivos do trabalho, diz respeito à determinação da pessoa e à sua conduta em relação aos outros, ao trabalho e às situações.

\subsection{As competências individuais}

As competências individuais reúnem aptidões, habilidades, comportamentos (posturas) manifestos e, ainda, o domínio e a aplicação de conhecimentos. Tais aptidões, quando desenvolvidas, transformam-se em habilidades (Resende, 2004).

Os conhecimentos adquiridos pela pessoa vêm à tona a partir do que ela define como "inteligência prática" e que é ampliada à medida em que aumenta a complexidade das conjunturas apresentadas.

A competência é, portanto, a manifestação do saber do indivíduo na prática. E uma vez que é possível ensinar e desenvolver novas competências, a organização possui novas possibilidades de moldar o comportamento de seus empregados, porém, além de ter o conhecimento, o indivíduo precisa estar disposto a realizar tal tarefa.

\subsection{Gestão por competências}

A organização orientada para o paradigma da gestão por competências é aquela particularmente hábil em "aprender a aprender" (Brito, 2008, p. 147). Nesse tipo de organização, o aprendizado não é meramente reativo, mas intencional, eficaz e conectado ao objetivo e à estratégia da organização.

Para Moura e Bitencourt (2006, p. 3), as competências organizacionais provêm da especificidade de cada empresa para identificar seus recursos e transformá-los em vantagem competitiva. Conseguirão destaque nesse mundo competitivo as organizações que souberem usufruir do seu capital intelectual de maneira organizada e dinâmica, respeitando as individualidades e convergindo as potencialidades de maneira que o aprendizado individual (AI) possa dar espaço ao aprendizado organizacional (AO). 
Um dos primeiros a desenvolver trabalhos nessa área foi McClelland (1973), ao publicar o artigo Testing for Competence rather than Intelligence, quando iniciou o debate sobre competência entre os psicólogos e os administradores nos Estados Unidos. Ele define a competência como uma característica subjacente a uma pessoa que é casualmente relacionada com desempenho superior na realização de uma tarefa ou em determinada situação.

McClelland (1987) desenvolveu seus trabalhos sobre o estudo dos aspectos comportamentais dos empreendedores ao longo de quase cinco décadas. Ele queria identificar quais aspectos ocorriam com essas pessoas que levavam à motivação para realizarem seus feitos. $\mathrm{O}$ autor passou a estudar quais características poderiam ser observadas e descritas, a fim de que outras pessoas pudessem, também, a partir dessa modelagem, obter os mesmos comportamentos empreendedores. Ele acreditava que desenvolver indivíduos com essas competências era ajudar a nação a se desenvolver.

Para responder ao crescimento econômico de uma nação, a motivação poderia ser um fator crucial. Para McClelland (1987), a motivação humana está compreendida em três necessidades dominantes: de realização, de afiliação e de poder.

Muylder, Falce e Pires (2013, p. 11) citam 10 características comportamentais dos empreendedores: busca de oportunidades e iniciativas; persistência; correr riscos calculados; exigência de qualidade e eficiência; comprometimento; busca de informações; estabelecimento de metas; planejamento e monitoramento sistemáticos; persuasão e rede de contatos; e independência e autoconfiança. Essas ações dizem respeito ao despertar do Intraempreendedorismo - uma das formas de empreendedorismo corporativo.

O papel da empresa, no entanto, passa por um viés de estimular, criar um ambiente propício à aprendizagem, inovação, criatividade, autonomia de realização e assunção de riscos, porém, como afirma Zarifian (2001), a empresa não pode obrigar ninguém a ser competente, pois ninguém é obrigado a ser empreendedor.

O grande diferencial desse aspecto é encontrar colaboradores que tenham atitude, pois ela define quase todos os comportamentos que o ser humano pode ter e, por esse motivo, tornase o principal componente da competência e está relacionada ao querer do indivíduo. Primeiro é preciso querer agir, e depois ter o conhecimento. Este, por sua vez, trata da capacidade de armazenamento de um conjunto de informações para ser usado em diversas situações.

Por fim, agir com talento, capacidade e técnica, obtendo resultados positivos é o que se chama de habilidade (Gramigna, 2002, p. 18). Feito isso, as pessoas estarão propensas ao desenvolvimento de mais e melhores competências. Com base nesses antecedentes se estabelece a primeira hipótese:

\section{H1 - As competências empreendedoras dos gestores de RH associam-se} positivamente ao nível de satisfação.

Quando os colaboradores percebem que as suas competências melhoram consideravelmente, sua satisfação e seus níveis de compromisso com a função e com a empresa tendem a alterar positivamente. De modo geral, as práticas de desenvolvimento de competências podem ser utilizadas como ferramentas importantes para aumentar o engajamento, o desempenho e a satisfação laboral (SARIDAKIS; TORRES; JOHNSTONE, 2013).

\section{Satisfação no trabalho}

O estudo sobre a satisfação no trabalho iniciou na década de 1930 (Klijn, 1998) e tem 
da percepção do trabalhador sobre seu trabalho. A satisfação no trabalho infere diretamente no desempenho da pessoa, em fatores como saúde física e mental, atitudes e comportamento profissional e social, tanto com repercussões na sua vida particular quanto dentro da organização.

As empresas precisam desenvolver um clima de trabalho que aumente a satisfação dos funcionários para que possam atingir desempenho superior, no entanto, apesar da criação desse ambiente favorável, é imprescindível que os funcionários conheçam o negócio, identifiquem oportunidades, conduzam projetos inovadores, implementem melhorias, assumam desafios e concentrem suas competências no atendimento de metas voltadas ao cumprimento da estratégia, melhoria da eficácia e busca de valor percebido por clientes e acionistas (HASHIMOTO, 2009).

Nesta seção visa-se responder à seguinte hipótese de pesquisa:

H2 - A satisfação no trabalho, para os gestores de RH, associa-se positivamente ao desempenho organizacional do setor.

Promover um bom clima interno para o trabalho se tornou um investimento altamente compensador pelos benefícios gerados com o aumento do desempenho das pessoas e, consequentemente, da organização (Hashimoto, 2009, p. 61).

A respeito da Teoria de Locke (1976), é possível identificar os fatores causais da satisfação no trabalho relacionados ao ambiente de trabalho, como eventos e condições e agentes: trabalho; pagamento; promoção; reconhecimento; condições e ambiente de trabalho; agentes colegas e subordinados; supervisão e gerenciamento; e empresa/organização (Martinez \& Paraguay, 2003, pp. 66-67).

O nível de satisfação no trabalho afeta o comportamento, sob forma de ausentismo, rotatividade, queda da produtividade, greves, acidentes de trabalho e dependência de álcool ou drogas (Locke, 1976; Pérez-Ramos, 1980; Zalewska, 1999a, 1999b).

\subsection{Teoria dos dois fatores de Herzberg}

Os autores que optam por adotar a distinção entre satisfação e insatisfação, de modo geral, pautam-se na Teoria da Motivação-Higiene de Herzberg (1959), ou Teoria dos Dois Fatores, que considera satisfação e insatisfação no trabalho como fenômenos de natureza diversa.

Martins e Santos (2006) apontam essa Teoria como a primeira que surgiu com o intuito de explicar a satisfação no trabalho. Ela pressupunha a existência de dois grupos de fatores, responsáveis, separadamente, pela satisfação no trabalho: - os motivadores -, como o próprio trabalho, o desempenho, a promoção e o reconhecimento pelo trabalho executado, e pela insatisfação no trabalho: - os higiênicos -, como supervisão, relações interpessoais no trabalho, política de organização e salário.

A maior contribuição de Herzberg, Mausner e Snyderman (1959) foi identificar a importância do crescimento psicológico como condição necessária para a satisfação no trabalho e demonstrar que esse crescimento vem do próprio trabalho (MARTINS; SANTOS, 2006, p. 196).

\section{Empreendedorismo e desempenho}

Empreendedores são pessoas que perseguem um benefício, trabalham individual e coletivamente, inovam, identificam e criam oportunidades de negócios, bem como montam e 
coordenam novas combinações de recursos (funções de produção) para extrair os melhores benefícios de suas inovações em um meio incerto (MORI, 1998).

Surge a premissa de que o profissional contemporâneo precisa se portar como uma empresa, em um contexto atual intitulado como "Eu S/A", de onde é parte de um contexto competitivo. Filion (1991) mantém apenas os elementos essenciais e define que "um empreendedor é uma pessoa que imagina, desenvolve e realiza visões."

Segundo Schumpeter (1991, p. 412), a função do empreendedor seria exatamente a de "fazer novas coisas ou de fazer as coisas que já vinham sendo feitas de novas maneiras."

\subsection{Intraempreendedorismo}

O termo Intraempreendedorismo surgiu como uma decorrência natural do empreendedorismo, na década de 1980, a partir dos estudos de Gifford Pinchot (LANA et al., 2013). Para Hartman (2006, p. 23-24), o intraempreendedorismo (empreendedorismo corporativo) ainda não é um conceito muito usual na prática nas organizações. Intraempreendedor (Intrapreneur), segundo Pinchot III (1987), é o chamado "Empreendedor Interno", aquele que consegue ser criativo, pensar em algo diferente a partir de um ambiente com liberdade, incentivo e recursos da empresa onde trabalha e dedica-se entusiasticamente a transformar as ideias em projetos de sucesso.

Hashimoto (2009) trouxe um comparativo entre as características do intraempreendedor e do funcionário. $\mathrm{O}$ funcionário possui um comportamento mais previsível, geralmente realiza tarefas em troca de recompensas financeiras, é conformado em conhecer somente sua tarefa e não tem entendimento sobre o todo; é pouco questionador, responde melhor mediante comando e tem medo de arriscar e pouco interesse em pensar algo diferente.

Por outro lado, o intraempreendedor é automotivado, entende o contexto do qual faz parte e faz bom uso deste, seus sonhos estão entrelaçados aos objetivos organizacionais, ele assume riscos calculados e aproveita as oportunidades; dá ideias inovadoras que geram valor à organização, tem iniciativa, é auto gerenciável, aprende com os erros e mantém relacionamentos construtivos.

Nesses cenários de inovação e mudança, o desafio das organizações não está voltado somente para a elaboração de planos, para que estes minimizem as incertezas, mas, principalmente, no intuito de identificar pessoas que saibam lidar com ambientes formados a partir de contextos mal definidos, com antecedência (Lenzi, Santos, Casado, \& Kuniyoshi, 2015).

A área de RH como principal agente de transformação de mudanças comportamentais precisa ser exemplo desse processo, precisa de intraempreendedores. Identificar quem são esses talentos, como se comportam e o que fazer para usufruir positivamente de suas competências passa a ser um fator preponderante do sucesso das organizações.

Considerando que o profissional de RH é fundamental para o processo de intraempreendedorismo, Muylder et al. (2013) afirmam que verificar a importância do empreendedor e seu papel como o ator indutor na organização é fundamental para o desenvolvimento de uma sociedade e de um negócio sustentável. Colocar em prática as competências empreendedoras é o que vai diferenciar os funcionários empreendedores.

A prática intraempreendedora pode ser dividida em vários níveis: vegetativo, bondoso, comprometido, inovador e visionário (Filion, 2004). No nível vegetativo estão os empregados e gestores que possuem o nível mínimo de intraempreendedorismo. No nível bondoso, estes pensam em coisas para melhorar, e no nível comprometido, eles as interiorizam para realizálas com perfeição. A inovação faz parte do seu processo de entrega e ele sente-se estimulado a aprender e a progredir continuamente, o que faz dele um visionário

\footnotetext{
. . . DOI:10.14211/xi-egepe-118052
} 
com o que fazem e devem ser capazes, pelo menos, de sustentar a continuidade da execução da ação que iniciam.

Com isso, visa-se responder à seguinte hipótese:

H3 - As competências empreendedoras dos gestores de RH associam-se positivamente ao desempenho do setor.

\subsection{Desempenho organizacional}

Para Brandão e Guimarães (2001, p. 8), "é possível inferir que a gestão de competências e a de desempenho devam ter como objetivo maior não somente a melhoria das performances profissional e organizacional, mas, principalmente, o desenvolvimento das pessoas em um sentido mais amplo." Somente assim representariam, ao mesmo tempo, um valor econômico para a organização e um valor social para o indivíduo. O desafio é fazer com que a empresa não seja somente "qualificada", do ponto de vista da competitividade, mas também "qualificante", "que ensina" no sentido de propiciar o "desenvolvimento das competências e a aprendizagem profissional." Enquanto a primeira "enfatiza a aquisição de rotinas e hábitos de trabalho", a segunda "enfatiza, pelo contrário, a instabilidade e a capacidade de evolução das situações, que passam a ser percebidas como fonte e oportunidade de aprendizagem." (ZARIFIAN, 2001, p. 111).

De acordo com Resende (2004), desempenho é a essência de qualquer atividade, significa atuação, performance. $\mathrm{O}$ gerente consegue avaliar as performances individuais pela evolução ou involução no desempenho das pessoas de sua equipe, obtendo nova base de informações.

A organização como um todo deve estar conectada a um todo maior que envolve a Gestão de Pessoas. Esse processo deve ser algo que envolva não apenas o RH como principal agente promotor da mudança, mas também os líderes da organização que farão jus a essa ferramenta como instrumento para gerir sua equipe desde o processo de selecionar, desenvolver, remunerar, promover e proporcionar feedback para que o processo de crescimento virtuoso da organização e colaborador seja contínuo.

\section{Método de pesquisa}

As empresas estão cada vez mais preocupadas em compor seus setores de RH, porque sabem que é com o apoio desses profissionais que será possível selecionar e reter os melhores talentos em seu negócio. Nesse sentido, conseguir profissionais capazes de contribuir com ideias, que sejam competentes, dinâmicos, provoquem mudanças e que permaneçam em suas organizações tem sido o desafio de tal setor. Assim, baseado no avanço de espaço e importância que a área de Recursos Humanos tem conquistado dentro das organizações, este estudo toma tal setor como ator principal utilizando as competências empreendedoras e o nível de satisfação com o trabalho dos profissionais de $\mathrm{RH}$, a fim de responder se entre estas existem relações positivas com o desempenho da área. Assim, institui-se a questão de pesquisa: Existe relação positiva entre as competências empreendedoras e o nível de satisfação dos profissionais de $R H$ e o desempenho dos setores de RH das micro e pequenas empresas da Cidade de Sobral? A pesquisa foi realizada a partir de uma população de 701 colaboradores, sendo 48 profissionais de RH e 653 funcionários de outros setores da empresa, em 35 empresas. Como critério de inclusão para participar da pesquisa, as empresas precisavam possuir o setor de $\mathrm{RH}$ em atuação com funcionários da própria empresa. Em relação aos procedimentos metodológicos, trata-se de uma pesquisa descritiva, de abordagem quantitativa. O levantamento das competências 
Cooley (1990). Já para a mensuração da satisfação no trabalho foi utilizado um instrumento baseado no Questionário de Satisfação no Trabalho S20/23, adaptado para o Brasil por Carlotto e Câmara (2008). Os resultados obtidos suportam as três hipóteses da pesquisa apresentadas anteriormente.

A escolha do porte das organizações em pequenas e médias ocorreu pelo quantitativo disponível a serem pesquisadas, considerando que Sobral é uma pequena cidade do interior do Ceará e não possui um número expressivo de empresas de grande porte. Outro fator que influenciou foi o acesso às PMEs ser um pouco mais fácil do que a grandes empresas. Por fim, um último fator decisório foi identificar como os setores de RH estavam estruturados, pois nas empresas de grande porte esse setor está claramente diferenciado.

O método serve de referência no processo de buscar explicações ou elaborar previsões acerca da problemática. Porém, antes mesmo de desenvolver o método, é necessário estabelecer os objetivos de forma clara, examinando de maneira ordenada as questões: Por que ocorre? Como ocorre? Quando ocorre? O que ocorre? (Oliveira, 2002). Segundo Lakatos e Marconi (2003), o método consiste em um conjunto de atividades sistêmicas e racionais que permitem o alcance do objetivo - conhecimentos válidos e confiáveis -, traçando o percurso a ser seguido, identificando os erros e auxiliando nas tomadas de decisões do cientista.

Este estudo é uma pesquisa experimental que busca descobrir uma verdade a partir de outras já conhecidas (Bastos et al., 2002). Para tanto, foram testadas as seguintes hipóteses:

H1 - As competências empreendedoras dos gestores de RH associam-se positivamente ao nível de satisfação no trabalho.

H2 - A satisfação no trabalho dos gestores de RH associa-se positivamente ao desempenho do setor.

H3 - As competências empreendedoras dos gestores de RH associam-se positivamente ao desempenho do setor.

Para investigar tais hipóteses optou-se pela estratégia descrita na próxima seção.

\subsection{Tipo e estratégia de pesquisa}

Para atender aos objetivos deste estudo optou-se por realizar uma pesquisa qualitativa e quantitativa com finalidade descritiva. Para tanto, foram realizadas entrevistas com gestores de RH e funcionários das empresas e um levantamento de dados por meio de uma survey com questionário. A partir da análise desses dados buscou-se compreender as relações entre as competências empreendedoras, satisfação no trabalho e desempenho organizacional nos RHs das empresas da região Norte do Ceará, na Cidade de Sobral.

De acordo com a classificação de Silva e Menezes (2001, p. 20), o presente trabalho, quanto a sua natureza, pode ser caracterizado como aplicado, ou seja, "visa gerar conhecimentos para aplicação prática, dirigida à solução de problemas específicos."

Objetivou-se identificar as competências empreendedoras relativas à função do Gestor de Recursos Humanos, bem como seu nível de satisfação no trabalho. Dessa forma, propõe-se a aplicação dos conhecimentos gerados a partir dos resultados da pesquisa como uma ferramenta de auxílio aos gestores das empresas no momento de contratar, capacitar e reter seus colaboradores da respectiva área.

Quanto à abordagem do problema, o estudo é quantitativo. Com os dados quantitativos é possível dispor de um panorama geral acerca do fenômeno investigado referente à sua capacidade de ilustrar uma realidade demográfica dentro do contexto em que se realizou. 
Ao considerar os objetivos do estudo, deve-se classificá-lo como descritivo, pois tem como finalidade a descrição das características pesquisadas de uma determinada população ou fenômeno, ou o estabelecimento de relações entre variáveis (Gil, 1999).

O levantamento de dados fez-se com questionário, um instrumento cientificamente desenvolvido para medir características importantes de indivíduos, empresas, eventos e outros fenômenos.

\subsection{População e técnicas de amostragem}

A população do estudo compreendeu os profissionais de Recursos Humanos em exercício nas PMEs instaladas na Cidade de Sobral. Como critério de inclusão para participar da pesquisa, as empresas precisariam possuir o setor de RH em atuação com funcionários da própria empresa.

A pesquisa foi realizada usando uma amostragem não probabilística, por acessibilidade. Essa condição impede o pesquisador de controlar o erro amostral, assim como de fornecer estimativas precisas da população (Mattar, 2001). Entretanto, possibilita avaliar as relações entre os construtos e atingir os objetivos propostos para este estudo.

Para compor a amostra inicialmente se registraram as empresas que existiam em Sobral conforme o levantamento do Serviço Brasileiro de Apoio às Micro e Pequenas Empresas (Sebrae, 2015), segundo seu porte mensurado pelo número de funcionários e diferenciados nos setores de indústria e comércio/serviços.

Tabela 1 - Classificação dos estabelecimentos segundo o porte

\begin{tabular}{lll}
\hline Porte da empresa & Indústria (pessoas) & Comércio/Serviços (pessoas) \\
\hline Micro & Até 19 & Até 9 \\
Pequena & De 20 a 99 & De 10 a 49 \\
Média & De 100 a 499 & De 50 a 99 \\
Grande & 500 ou mais & 100 ou mais \\
\hline
\end{tabular}

Fonte: Sebrae (2015).

Segundo registros mais atuais do Instituto Brasileiro de Geografia e Estatística (IBGE, 2016), existem 3.346 unidades de negócios atuantes na Cidade de Sobral entre micro, pequenas, médias e grandes empresas. Ao todo 70 empresas foram listadas com potencial inicial para participação na pesquisa. Porém, durante o primeiro contato, por telefone, para averiguação dos pré-requisitos de participação, somente 60 delas admitiram possuir o setor em sua estrutura organizacional.

Desse conjunto de empresas, somente 35 aceitaram participar da pesquisa, e destas houve retorno de apenas 25 empresas, totalizando 48 funcionários do setor de RH e 653 funcionários de outros setores. A pesquisa ocorreu entre julho e setembro de 2016.

\subsection{Método e técnicas de coleta de dados}

Por se tratar de uma survey descritiva, para a coleta dos dados foi utilizada a técnica do questionário de autopreenchimento. As perguntas utilizadas na pesquisa foram fechadas, o que possibilitou maior facilidade na tabulação e análise dos dados.

O questionário foi enviado por e-mail ou impresso, de acordo com a solicitação de cada empresa, e os representantes de RH foram os responsáveis por seu recebimento e aplicação.

Ao todo foram distribuídos quatro questionários para cada participante. Um sobre Satisfação no Trabalho, um sobre Competências Empreendedoraşoum sobre Desempenho ${ }_{i}$ do 
profissionais de $\mathrm{RH}$, e o de Desempenho do $\mathrm{RH}$ também pelos funcionários da empresa, de maneira sigilosa e voluntária.

Em relação à avaliação sobre a Satisfação no Trabalho foi utilizado um instrumento baseado no Questionário de Satisfação no Trabalho S20/23, de Meliá e Peiró (1989), fundamentado no modelo teórico de Locke (1984). O questionário foi validado e adaptado para o Brasil por Carlotto e Câmara (2008) em uma amostra de 640 trabalhadores das áreas da saúde (27,7\% - médicos, enfermeiros, auxiliares administrativos) e da educação (72,3\% - professores universitários, de ensino médio e fundamental) da região metropolitana de Porto Alegre, RS.

A ocorrência de satisfação no trabalho foi estimada pelo cálculo da média das pontuações obtidas em cada dimensão, indicando o índice alcançado em cada uma delas.

\subsection{Análise dos dados}

A partir da análise dos dados buscou-se caracterizar como se apresentavam as competências empreendedoras nos gestores de RH e qual seu nível de satisfação no trabalho. Procurou-se entender que importância possuem as competências e sua satisfação no trabalho para o desempenho do gestor de RH em relação ao desempenho organizacional. Também foi analisado seu perfil e como este influencia as competências empreendedoras ou a satisfação no trabalho.

Os dados levantados foram tabulados em planilha Excel ${ }^{\circledR}$ e analisados usando-se o software STATISTICA®. Com o auxílio da planilha, os dados coletados foram organizados, tendo como primeiro procedimento a tabulação e a identificação de dados faltantes, que foram preenchidos com a mediana da variável considerada.

Em sequência, estimou-se a média, o desvio padrão, o coeficiente de variação, a assimetria e a curtose de cada variável. Os cálculos da assimetria e curtose têm como finalidade avaliar a normalidade de suas distribuições (Hair, Black, Babin, Anderson, \& Tatham, 2009), em particular por que os dados provinham de escalas tipo Likert, que dificilmente têm distribuição normal. Segundo propõem Finney e Di Stefano (2006), dados com coeficientes de até 2 de assimetria e até 7 de curtose, em módulo, podem ser considerados quase normais.

Findos esses procedimentos de estatística descritiva, os métodos inferenciais usados foram análise de variância (ANOVA) e análise de correlação.

\subsubsection{Análise da Variância}

Para o desenvolvimento de análise da variância foram categorizadas as variáveis de modo a dispor de preditores categóricos. Para tanto, as categorias foram definidas usando os quartis e a mediana. Assim, desde o valor mínimo até o quartil inferior se definiu a categoria muito baixo (MB), desde o quartil inferior até a mediana se considerou baixo (B), da mediana até o quartil superior foi tratado como um valor alto (A) e acima do quartil superior até o máximo, como muito alto (MA).

Todas as ANOVAs foram univariadas (one-way Anova) e se estabeleceu o nível de significância de 5\% $(\alpha=0,05)$. As comparações pareadas, no caso de ter que rejeitar a hipótese de igualdade simultânea das médias, foi feita usando o teste a posteriori (post-hoc) de Duncan.

\section{Análise dos resultados}

Os resultados descritivos das variáveis observadas obtidas na coleta de dados, iniciandose pelas tabelas de frequência relativa às variáveis categóricas, inicialmente apresentam-se ao perfil dos respondentes. 
Entre os 43 profissionais das 23 empresas observou-se que o percentual maior de respondentes é do gênero feminino $(74,42 \%)$.

Quanto à idade dos respondentes, houve predominância de mulheres entre 25 e 35 anos, e a menor concentração de respondentes ficou na faixa etária de 45 a 60 anos.

A maior parte dos respondentes possui formação superior e pós-graduação, encontrando-se o número maior (25) no gênero feminino. Um respondente feminino não respondeu.

Relacionado à distribuição de gênero quanto ao cargo, os cargos de Supervisor, Coordenador, Gerente e Diretor são ocupados por 13 respondentes do gênero feminino e três do gênero masculino. Entre os Técnicos e Assistentes, cargo de maior predominância, 12 são mulheres e sete são homens. Há também oito Analistas, dois quais sete são do gênero feminino.

Sobre o ramo da empresa, os resultados apontam que 56,52\% das empresas da amostra são do ramo de Prestação de Serviços, e 26,08\% dos funcionários trabalham no ramo do Comércio, e os demais entre Indústria e mista.

Com relação ao tempo de empresa dos profissionais de $\mathrm{RH}$, a pesquisa apontou que a maioria está entre menos de um e cinco anos e que dos 43 respondentes, 19 (44,18\%) têm no máximo três anos de efetivado.

Quanto à distribuição quanto ao tempo de experiência na função, a maior parte dos profissionais (23) possui mais de três anos de experiência na função. Um respondente deixou em branco.

A respeito da distribuição de gênero quanto à remuneração, a renda de até quatro salários é a de maior predominância, com $36(83,72 \%)$ respondentes. Somente sete possuem renda acima de quatro salários.

Das 23 empresas com respostas válidas, $60,86 \%$ possuem no máximo até três funcionários no setor de RH, e $39,14 \%$ possuem quatro ou mais funcionários.

No apontamento de quantos subsistemas de RH existiam dentro das empresas em funcionamento, o Departamento Pessoal (DP) funciona em 82,60\% das empresas pesquisadas, e o Recrutamento e Seleção (RS) está presente em 78,26\% das empresas. O setor de menor destaque e implantação nas empresas em questão é o de Remuneração e Performance, ocupando somente $21,73 \%$ das 23 empresas.

As competências dos gestores foram avaliadas em três blocos: conjunto de realização (valor máximo 75 pontos), conjunto de planejamento (valor máximo 45 pontos) e conjunto de poder (valor máximo 30 pontos), no total geral máximo de 150 de pontos. Os gestores de RH se auto avaliaram com as médias de notas em conjunto de realização (62 pontos), conjunto de planejamento (35 pontos) e conjunto de poder ( 22 pontos). Na média da avaliação geral das Competências Empreendedoras (CEs) eles atribuíram a si mesmos 119 de pontuação. As competências em que os gestores de RH atribuíram a maior pontuação a si foram Exigência por Qualidade e Eficiência (EQE), Persistência (PER) e Comprometimento (COM).

Com relação ao quesito de satisfação no trabalho, o instrumento de Carlotto e Câmara (2008), com 20 itens, possui três dimensões: satisfação com as relações hierárquicas (SRH) (11 itens); satisfação com o ambiente físico de trabalho (SAFT) (cinco itens); e satisfação intrínseca com o trabalho e oportunidades de crescimento (SITOPC) (quatro itens). A pontuação total poderia somar 100 pontos, considerando que cada item vale até cinco. As médias obtidas na autoavaliação dos gestores de RH foram de 46 pontos para SRH de um máximo possível de 55; para SAFT ela atingiu 22 pontos de um total de 25; e para o conjunto SITOPC a média foi de 17 pontos de um total de 20 . A dimensão que teve a menor proporção foi a satisfação com as relações hierárquicas $(\mathrm{SRH})$. 
Com os dados obtidos para as Competências Empreendedoras (CE) foi realizada uma análise de variância univariada (One-way ANOVA) para cada um dos conjuntos, isto é, para Realização, Planejamento e Poder. Para a Satisfação no Trabalho (ST) fez-se o mesmo procedimento. Trabalhou-se cada dimensão de modo individual, ou seja, satisfação com as relações hierárquicas (SRH), satisfação com o ambiente físico de trabalho (SAFT), satisfação intrínseca com o trabalho e oportunidades de crescimento (SITOPC) e satisfação geral.

Quando a comparação simultânea foi significativa, isto é, quando alguma média se diferenciou entre os grupos, foi utilizado o teste de Duncan para identificar, entre todos os pares possíveis, quais se diferenciam entre si. Nas comparações simultâneas optou-se por trabalhar com representações gráficas, assinalando as diferenças pelo valor $\mathrm{p}$ no cálculo da estatística $\mathrm{F}$. As significâncias adotadas foram $10 \%$ e $5 \%$ ( $\mathrm{p}<0,10$ ou $\mathrm{p}<0,05)$.

O uso de significância de $10 \%$ está relacionado ao fato de os dados proverem de um levantamento da percepção dos respondentes mensurada por uma escala tipo Likert de cinco pontos. Ou seja, as respostas são registradas como uma opção de escolha entre os extremos de ótimo a ruim, de sempre a nunca ou de totalmente satisfeito a totalmente insatisfeito, que, embora não sendo valores, associaram-se a uma escala numérica. Assim, em Ciências Sociais é aceitável trabalhar com significâncias de $10 \%$, em especial quando a pesquisa é suportada pela percepção do respondente.

\subsection{Teste de hipótese}

Para realizar os testes de hipóteses, ou seja, avaliar se existe relação entre os constructos considerados no estudo, primeiro verificou-se se as distribuições que os representam possuíam normalidade. Para tanto, efetuaram-se os somatórios das pontuações dos itens que compõem os conjuntos das competências empreendedoras e o somatório total dos três conjuntos, o somatório de três questões do desempenho, a nota que os gestores deram ao desempenho do setor e o somatório de todas as questões referidas à satisfação.

Criada uma base de dados com essas novas variáveis, denominadas conjunto realização, conjunto planejamento, conjunto poder, competências empreendedoras, questões de desempenho, nota de desempenho e questões de satisfação, realizou-se o teste de normalidade para cada uma delas por meio do teste de Shapiro-Wilk. Os resultados obtidos estão na Tabela 2 , em que se pode constatar que nenhuma das distribuições cumpre os quesitos de normalidade.

Tabela 2 - Teste de normalidade para as variáveis representativas dos constructos

\begin{tabular}{ll}
\hline Variáveis & Teste Shapiro-Wilk \\
\hline Conjunto Realização & $\mathrm{p}=0,0036$ Rejeitada \\
Conjunto Planejamento & $\mathrm{p}=0,0008$ Rejeitada \\
Conjunto Poder & $\mathrm{p}=0,0494$ Rejeitada \\
Competências Empreendedoras & $\mathrm{p}=0,0004$ Rejeitada \\
Questões de desempenho & $\mathrm{p}=0,0170$ Rejeitada \\
Nota de desempenho & $\mathrm{p}=0,0006$ Rejeitada \\
Questões de satisfação & $\mathrm{p}=0,0177$ Rejeitada \\
\hline
\end{tabular}

Fonte: os autores.

Em face aos resultados obtidos, para avaliar se as hipóteses de pesquisa se confirmam empregou-se um coeficiente de correlação não paramétrico - o coeficiente de posto de Spearman (rank $R)$.

Tabela 3 - Correlações de Spearman entre as variáveis que representam os constructos analisados 


\begin{tabular}{llllllll}
\hline Variáveis & CR & CPI & CPo & C E & Q D & N D & Q S \\
\hline Conjunto Realização & 1 & 0,704 & 0,455 & 0,861 & 0,110 & 0,186 & 0,126 \\
Conjunto Planejamento & $\mathrm{p}<0,05$ & 1 & 0,660 & 0,934 & 0,157 & 0,335 & 0,404 \\
Conjunto Poder & $\mathrm{p}<0,05$ & $\mathrm{p}<0,05$ & 1 & 0,735 & $-0,011$ & 0,135 & 0,226 \\
Competências Empreendedoras & $\mathrm{p}<0,05$ & $\mathrm{p}<0,05$ & $\mathrm{p}<0,05$ & 1 & 0,150 & 0,284 & 0,329 \\
Questões de desempenho & $\mathrm{ns}$ & $\mathrm{ns}$ & $\mathrm{ns}$ & $\mathrm{ns}$ & 1 & 0,775 & 0,221 \\
Nota de desempenho & $\mathrm{ns}$ & $\mathrm{p}<0,05$ & $\mathrm{~ns}$ & $\mathrm{p}<0,10$ & $\mathrm{p}<0,05$ & 1 & 0,393 \\
Questões de satisfação & $\mathrm{ns}$ & $\mathrm{p}<0,05$ & $\mathrm{~ns}$ & $\mathrm{p}<0,10$ & 0,221 & $\mathrm{p}<0,05$ & 1 \\
\hline
\end{tabular}

Fonte: os autores.

Os resultados exibidos na Tabela 3 apresentam que as competências empreendedoras em conjunto se associam com a satisfação no trabalho, com $10 \%$ de significância (rank $R=0,329$ ), corroborando a $\mathrm{H} 1$. Por sua vez, ao considerar os conjuntos de competências, somente o de planejamento apresenta correlação significativa ao 5\%, com um coeficiente rank $R=0,404$.

A segunda hipótese de pesquisa a considerar afirma que a satisfação no trabalho dos gestores de RH associa-se positivamente ao desempenho do setor (H2). Nesse sentido, o desempenho pode ser considerado por dois pontos de vista. O primeiro é derivado do somatório de três questões que tratam da segurança no ambiente de trabalho, dos benefícios oferecidos e do atendimento (na Tabela são chamadas questões de desempenho), e o segundo é a nota que os gestores deram ao desempenho.

Observando a Tabela 3 confirma-se que essas duas formas de considerar o desempenho se correlacionam entre si com 5\% de significância (rank $R=0,775$ ). Contudo, ao analisar como se relacionam com a satisfação no trabalho, apenas a nota tem correlação positiva significante ao $5 \%$ ( $\operatorname{rank} R=0,393)$.

Por fim, a terceira hipótese de pesquisa conjectura que as competências empreendedoras dos gestores de RH associam-se positivamente ao desempenho do setor. E, como no caso anterior, o desempenho pode ser considerado pelo somatório das três questões ou pela nota que os gestores atribuíram ao setor.

Ainda na Tabela 2, percebe-se que as competências empreendedoras expressas como o somatório total vinculam-se apenas à nota dada pelos gestores ao desempenho com uma significância de $10 \%$ (rank $R=0,284$ ), pelo que se confirma a H3. E quando se avaliam as associações dos conjuntos com o desempenho, como se verifica para a satisfação, somente é o conjunto de planejamento que se correlaciona positiva e significativamente ao $5 \%$ com a nota ( $\operatorname{rank} R=0,335)$.

\section{Conclusões e recomendações}

Em relação aos resultados pertinentes à satisfação no trabalho, observou-se que a satisfação intrínseca com o trabalho e oportunidade de crescimento (SITOPC) está diretamente relacionada ao nível de competências empreendedoras dos gestores de RH, ou seja, quanto mais satisfeitos com seu trabalho e com maiores chances de crescer na empresa maior será a dedicação desses profissionais em se profissionalizarem e melhorarem suas competências. Ao mesmo tempo, foram identificadas as competências relacionadas ao conjunto de Poder, em que os profissionais que possuem alto poder de influência e gostam de autonomia e independência são os que possuem alto índice de satisfação no ambiente de trabalho.

$\mathrm{O}$ conjunto de Planejamento se mostrou mais desenvolvido naqueles profissionais em que o nível de satisfação com as relações hierárquicas (SRH) foi muito alto, confirmando que as relações entre líder e subordinado são importantes para o que o profissional consiga fazer um bom planejamento do seu trabalho.

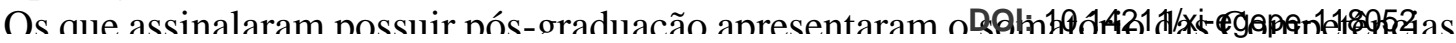


que a formação é um quesito importante para ocupação do cargo e aderência às competências. Quanto ao tempo de empresa, os profissionais de RH com três a cinco anos possuem o conjunto de Realização significativamente mais desenvolvido que os demais. Os profissionais que indicaram ganhar quatro salários ou mais possuem o somatório das Competências Empreendedoras e o conjunto de Planejamento e Poder mais desenvolvidos. A satisfação no trabalho é decorrente das recompensas financeiras (LICHT, 1990; PÉREZ-RAMOS, 1980).

Avaliando os processos de RH, aqueles profissionais que apontaram possuir segurança do trabalho $(\mathrm{ST})$, recrutamento e seleção $(\mathrm{R} \& \mathrm{~S})$ e remuneração e performance $(\mathrm{R} \& \mathrm{P})$ tiveram somatório das Competências Empreendedoras desenvolvidas, tendo como destaque o conjunto de planejamento. Aos que apontaram cinco dos seis subsistemas na empresa o conjunto de Realização foi mais desenvolvido.

Com relação à primeira hipótese, se existe relação positiva entre as competências empreendedoras dos gestores de RH e o nível de satisfação no trabalho, o estudo apontou que, quando vistas juntas, a relação é positiva, porém, quando tratadas em conjunto, somente o conjunto de planejamento teve relação positiva. Considerando-se a segunda hipótese, em que a satisfação no trabalho dos gestores de RH associa-se positivamente ao desempenho do setor, também foi constatada sua veracidade.

Para a terceira hipótese, em que se conjectura que as competências empreendedoras dos gestores de RH se associam positivamente ao desempenho do setor, também se obteve uma confirmação, ao mesmo tempo em que ficou evidente o forte índice do conjunto de planejamento, quando analisado separado das demais competências, como o único com impacto significativo sobre o desempenho, assim como foi percebido quando comparado à satisfação no trabalho.

$\mathrm{O}$ estudo aponta para um RH tradicional, voltado a rotinas, procedimentos, regras e controles. Pouquíssimas das empresas pesquisadas conseguem agir em todos os subsistemas de RH, tendo como foco de trabalho o Departamento Pessoal, Benefícios e Segurança do Trabalho. Esses aspectos fortalecem inclusive as competências que mais tiveram destaque, como impactos nas relações positivas com o desempenho e satisfação, que foram as voltadas ao Planejamento, no qual esses profissionais precisam desenvolver a Busca pelas Informações (BDI), o Estabelecimento de Metas (EDM) e o Planejamento e Monitoramento Sistemáticos (PMS).

Considerando que a representatividade empresarial envolvida no estudo foi somente das pequenas e médias empresas e que se concentrou em uma única cidade, sugere-se a continuação com outras empresas e em maior escala de abrangência, expandindo o espectro inclusive para outras localidades do País.

Implica-se deixar como sugestão um olhar mais apreciativo ao RH por parte das empresas, pois sem as competências necessárias e diante de um ambiente pouco estimulador para sua satisfação, os funcionários terão seu desempenho comprometido e perderão a oportunidade de usar todo o seu potencial.

\section{Referências}

Bastos, C. L. (2002). Aprendendo a aprender: introdução à metodologia científica (16a ed.). Petrópolis: Vozes.

Brandão, H. P., \& Guimarães, T. A. (2001). Gestão de competências e gestão de desempenho: tecnologias distintas ou instrumentos de um mesmo constructo? Revista de Administração de Empresas, 41(1), 8-15.

Brito, L. M. P. (2008, julho-dezembro). Gestão de Competências Gestãa do do Conhecimento e 
do trabalhador. Cadernos de Educação, 203-225.

Carlotto, M. S., \& Câmara, S. G. (2008). Propriedades psicométricas do questionário de satisfação no trabalho (S20/23). Psico-USF,12(2), 203-210.

Cooley, L. (1990). Entrepreneurship training and the strengthening of entrepreneurial performance. Washington: USAID.

Dutra, J. S. (2004). Competências: conceitos e instrumentos para a gestão de pessoas na empresa moderna (1a ed.). São Paulo: Atlas.

Filion, L. J. (2004). Entendendo os intraempreendedores como visionistas. Revista de Negócios, 65-80.

Filion, L. J. (1991). O Planejamento do seu Sistema de Aprendizagem Empresarial Identifique uma visão e avalie o seu sistema de relações. $R A E, 31(3), 63-71$.

Finney, S. J., \& DiStefano, C. (2006). Non-normal and categorical data in structural equation modeling. In G. R. Hancok, \& R. O. Mueleer. Structural equation modeling: a second course. Charlotte, NC: Information Age Publ.

Fleury, A., \& Fleury, M. T. (2001). Construindo o conceito de competência. RAC, edição especial.

Gil, A. C. (1999). Métodos e técnicas de pesquisa social (5a ed.). São Paulo: Atlas.

Gramingna, M. R. (2002). Modelo de Competências e Gestão dos Talentos. São Paulo: Editora Pearson.

Hair Jr., J. F., Black, W. C., Babin, B. J., Anderson, R. E., \& Tatham, R. L. (2009). Análise multivariada de dados (5a ed.). Porto Alegre: Bookman.

Hartman, A. (2006). Avaliação da cultura intraempreendedora: desenvolvimento e teste de uma metodologia (Dissertação de Mestrado, Universidade Tecnológica do Paraná, Ponta Grossa).

Hashimoto, M. (2009). Organizações intraempreendedoras: construindo a ponte entre clima interno e desempenho superior (Tese de Doutorado, Fundação Getúlio Vargas, São Paulo).

Herzberg, F., Mausner, B., \& Snyderman, B. (1959). The motivation to work. NewYork: Willy.

Instituto Brasileiro de Geografia e Estatística. (2016). Cadastro central de empresas 2014. Rio de Janeiro: IBGE.

Klijn, T. M. P. (1998). Satisfação no trabalho de mulheres acadêmicas da Universidade de Concepción, Chile (Tese de Doutorado, Escola de Enfermagem de Ribeirão Preto e Escola de Enfermagem da Universidade de São Paulo, Ribeirão Preto SP). 
Lakatos, E. M., \& Marconi, M. A. (2003). Fundamentos de metodologia científica (5a ed.). São Paulo: Atlas.

Lana, J., Orlandi, C., Camargo, M., Aparecida Branco, M., \& Lenzi, F. C. (2013). A relação das competências empreendedoras e da conduta intraempreendedora no setor de serviços educacionais. Revista Pensamento Contemporâneo em Administração, 7(2), $77-95$.

Lenzi, F. C., Santos, S. A., Casado, T., \& Kuniyoshi, M. S. (2015). Empreendedores Corporativos: Um estudo sobre a associação entre Tipos Psicológicos e Competências Empreendedoras em empresas de grande porte de Santa Catarina - Brasil. Revista de Administração da UNIMEP, 13(2), 117-141. Doi:10.15600/16795350/rau.v13n2p117-141

Licht, R. H. (1990). Satisfação, responsabilidade e sentido no trabalho: um estudo preliminar de associação (Dissertação de Mestrado, Universidade de São Paulo, São Paulo).

Locke, E. A. (1984). Job satisfaction. In M. Gruneberg, \& T Wall. (Orgs.), Social psychology and organizational behavior (pp. 93-117). New York: John Wiley and Sons.

Locke, E. A. (1976). The nature and causes of job satisfaction. In M. D. Dunnette (Ed.), Handbook of industrial and organizational psychology (pp. 1297-1349). Chicago: Rand McNally.

Martinez, M. C., \& Paraguay, A. I. B. B. (2003). Satisfação e saúde no trabalho: aspectos conceituais e metodológicos. Cadernos de Psicologia Social do Trabalho, 6, 59-78.

Martins, M. C. F., \& Santos, G. E. (2006). Adaptação e validação de construto da Escala de Satisfação no Trabalho. Psico-USF, 11(2), 195-205.

Mattar, F. N. (2001). Pesquisa de marketing (3a ed.). São Paulo: Atlas.

Medeiros, S. A., Santos P. C. F., Dantas, A. B., \& Minuzzi, J. (2007). Satisfação no Trabalho como Indicador de Desempenho Estratégico Organizacional. Anais do Encontro Nacional De Engenharia De Produção, Foz do Iguaçu, 27, 1-10.

Meliá, J. L., \& Peiró, J. M. (1989). La medida de la satisfacción laboral em contextos organizacionales: el cuestionario de satisfacción. Psicologemas, 5, 59-74.

McClelland, D. (1987). Characteristics of successful entrepreneurs. The Journal of Creative Behavior, 21(3), 219-233.

McClelland, D. (1973). Testing for competence rather than intelligence. American Psychologist, 28(1), 1-14.

Mori, F. (Org.). (1998). Empreender: identificando, avaliando e planejando um novo negócio. Florianópolis: ENE.

Moura, M. C. C., \& Bitencourt, C. C. (2006). A articulação entre estratégia e e 99i-egepe-118052 
Muylder, C. F., Falce, J. L., \& Pires, A. M. (2013). Influência do perfil empreendedor na gestão de uma instituição de ensino. Amazônia, Organizações e Sustentabilidade, 2(2), 7-18.

Oliveira, S. L. (2002). Tratado de metodologia científica: projetos de pesquisa, TGI, TCC, monografias, dissertações e teses. São Paulo: Pioneira Thomson Learning.

Pérez-Ramos, J. (1980). Satisfação no trabalho: metas e tendências (Tese de Livre-docência, Universidade Estadual Júlio de Mesquita Filho, Assis).

Pinchot III, G. (1987). Innovation through intrapreneuring. Research Management, 30(2).

Resende, E. (2004). A força e o poder das competências conecta e integra: competências essenciais; competências das pessoas; competências de gestão, competências organizacionais. Rio de Janeiro: Qualitymark.

Saridakis, G., Torres, R. M., \& Johnstone, S. (2013). Do human resource practices enhance organizational commitment in SMEs with low employee satisfaction? British Journal of Management, 24, 445-458.

Schumpeter, J. A. (1991). Comments on a plan for the study of entrepreneurship. In: Swedgerg, R. (Eds.), Joseph A. Schumpeter: the economics and sociology of capitalism (pp. 406-428). Princeton: Princeton University Press.

Serviço Brasileiro de Apoio às Micro e Pequenas Empresas. (2015). Anuário do trabalho na micro e pequena empresa. São Paulo: DIEESE.

Selltiz, C., Wrightsman, L. S., \& Cook, S. W. (1965). Métodos de pesquisa das relações sociais. São Paulo: Herder.

Silva, E. L., \& Menezes, E. M. (2001). Metodologia da pesquisa e elaboração de dissertação (3a ed.). Florianópolis: UFSC/PPGEP/LED.

Triviños, A. N. S. (1987). Introdução à pesquisa em ciências sociais: a pesquisa qualitativa em educação. São Paulo: Atlas.

Zalewska, A. M. (1999a). Achievement and social relations values as conditions of the importance of work aspects and job satisfaction. International Journal of Occupational Safety and Ergonomics, 5(3), 395-416.

Zalewska, A. M. (1999b). Job satisfaction and importance of work aspects related to predominant values and reactivity. International Journal of Occupational Safety and Ergonomics, 5(4), 485-511.

Zarifian, P. (2001). Objetivo competência: por uma nova lógica. São Paulo: Atlas. 